\title{
Evaluation of Juniperus communis L. seed extract on benign prostatic hyperplasia induced in male Wistar rats
}

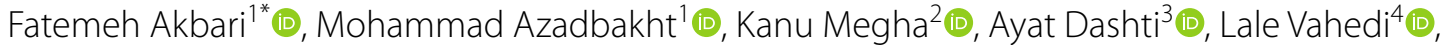

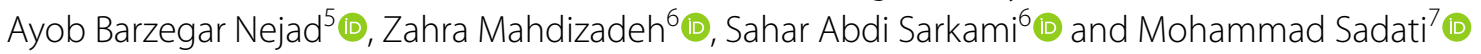

\begin{abstract}
Background: Benign prostatic hyperplasia (BPH) is a common disease which causes various health problems for elderly men such as urinary retention, recurring urinary tract infection and bladder stones. The aim of this study is to evaluate the therapeutic effects of Juniperus communis L. seed extract (JCS) on BPH in male Wistar rats.

Methods: To this end, 30 rats were divided into 5 groups $(N=6)$ : group 1 (vehicle), group 2 (disease control), group 3 (standard medicine; $10 \mathrm{mg} / \mathrm{kg}$ finasteride), and groups 4 and 5 were treated with $300 \mathrm{mg} / \mathrm{kg}$ and $600 \mathrm{mg} / \mathrm{kg}$ of the hydroalcoholic JCS seed extract, respectively. Groups 2, 3, 4 and 5 received testosterone enanthate to induce prostatic hyperplasia. At the end of experimental period (28 days), prostate glands were cut off under anesthesia. Histopathological examination was done and biochemical parameters such as Malondialdehyde, Glutathione and protein carbonyl were also measured. Their body weights were also observed during the study. At the end of the experiment, prostate weights and prostate specific antigen (PSA) levels were measured. Prostate index, inhibition prostate weight and inhibition prostate index were also calculated.
\end{abstract}

Results: Both histopathological examination and biochemical parameter results showed significant improvements in rats treated with finasteride and $600 \mathrm{mg} / \mathrm{kg}$ JCS extract $(p<0.01)$. In addition, PSA levels showed significant decrease in comparison with the disease group. But acute toxicity test indicated that using JCS extract resulted in an increase in liver enzymes (ALP, LDH, SGOT, SGPT). As a result, the extract should be used with caution.

Conclusions: Oral administration of JCS extract is effective on preventing testosterone-induced benign prostatic hyperplasia.

Keywords: Benign prostatic hyperplasia, Oxidative stress, Prostate specific antigen, Juniperus communis L, Herbal medicine

\section{Background}

Benign prostatic hyperplasia (BPH) is a common aggressive disease which has a high prevalence in middleaged and elderly men. The prevalence among men aged between 50 and 60 is $60 \%$, which increases up to $70 \%$ in

\footnotetext{
*Correspondence: akbariftm@yahoo.com

1 Department of Pharmacognosy, Faculty of Pharmacy, Mazandaran University of Medical Sciences, 17th Kilometer of Farah Abad Street, 47178-43611 Sari, Iran

Full list of author information is available at the end of the article
}

men aged between 60 and $70 . \mathrm{BPH}$ is the most common cause of urinary obstruction in men [1]. BPH is characterized by the enlargement of the prostate gland due to an increase in stromal and epithelial cellular counts. This can cause many health problems for elderly men such as urinary retention, recurring urinary tract infection, urinary irritation, and it can even lead to bladder stones [2].

Many factors can contribute to the development of this disease such as excessive androgen hormones, old age and dietary lifestyle. Androgen and appendage 
hormone play key roles in the development of this pathological condition. As a result, excessive androgen hormone can be observed in patients, but all cases of excessive androgen do not necessarily suffer from this disease. This indicates that androgen does not directly cause BPH [3]. Studies have shown that dietary lifestyle can play an important role in the development of $\mathrm{BPH}$; foods containing nitrogen can increase the risk of getting the disease [4]. Furthermore, the connection between BPH and metabolic diseases such as diabetes, high blood pressure, and obesity is verified [5].

The aromatase enzyme and 5-alpha reductase activity increase with age [6]. This enzyme is responsible for the conversion of androgens to estrogen and dihydrotestosterone $[7,8]$. As a result, testosterone levels decrease, but this hormone's metabolites (estrogen and dihydrotestosterone) increase. Estrogen plays an important role in the growth of a cell and in increasing prostate cells [8]. Dihydrotestosterone works locally by binding to androgen receptors in the cell nuclei, and signals the transcription of growth factors that are mitogenic to the epithelial and stromal cells [9]. The combined effect of both hormonal factors can cause prostatic hyperplasia [10].

According to this theory, fibrosis and weakening of prostate muscle tissue increase the risk of the disease. This means that weakening the prostate muscle, which plays an important role in discharging and excreting the fluid produced by this gland, causes fluid accumulation in the gland and this can make further damages to the myofibrous tissue of the muscle $[11,12]$. Due to the fact that the muscle cells of the tissue cannot proliferate, collagen fibers try to repair and fill the damaged tissue. Replacing collagen fibers in the tissue results in poorer muscle tissue function. This defective cycle of progressive muscle tissue fibrosis and fluid accumulation are the major causes of prostate enlargement in benign prostatic hyperplasia [11].

Despite the efforts in medication therapy, there is still a need to find an effective treatment for this disease which can deal with it with higher potency and fewer complications in the long run [13]. To this end, this study aimed to examine a medicinal plant called "Juniperus communis L... Juniperus communis L., which belongs to the Cupressaceae family, is an evergreen tree or shrub which has lancet, triangular and green leaves with a central white strip. Its fruit is spherical and fleshy which is initially green in color and then changes into dark purple with a blue waxy coating. Juniperus communis is native to the north of Iran and its fruit contains phenolic and terpenoid compounds [14].

Juniperus extract components were identified by comparing HPLC retention times, UV-vis spectra and MS fragmentation patterns with pure substances and with those identified in other researches [15].

Phenolic compounds such as Catechin, Rutin, Hyperoside, Rosmarinic acid and Amentoflavone were identified and quantified in aqueous berry extract by high performance liquid chromatography (HPLC) [15]

Juniperus communis essential oil contains monoterpene hydrocarbons such as $\alpha$-pinene, myrcene, sabinene limonene and $\beta$-pinene. These essential oils can be extracted by supercritical $\mathrm{CO}_{2}$ extraction or using a hydro-distillation Clevenger apparatus, and can be detected by capillary gas chromatography using flame ionization (GC-FID) and mass spectrometric detection (GC-MS) [16]. These essential oils have strong ROS scavenging activity. This antioxidant property has been reported in in vitro and in vivo conditions and in yeast cell [17]. Phytosterols can be found in stems, needles, green berries and ripe berries of Juniperus communis. Ripe berries contain 5\% campesterol and stigmasterol, and more than $20 \% \beta$-sitosterol. Juniperus communis have been in use since ancient times and Ayurvedic physicians still prescribe it because of its contraceptive properties. Studies have shown its abortifacient properties in in vivo conditions [18]. Due to this phytosterols property and traditional usage, the present study was conducted to evaluate the efficacy of Juniperus communis on one of sex hormone diseases, namely the benign brostatic hyperplasia $(\mathrm{BPH})$.

\section{Methods}

\subsection{Preparation of hydroalcoholic Juniperus communis seed (JCS) extract}

The seeds were collected from trees in the Hezar Jarib area of Neka (latitude 36.623130; longitude 53.353036) and were identified by Mohammad Azadbakht. The herbarium specimen was also prepared and placed in the herbarium department of Pharmacognosy of Faculty of Pharmacy.

The seeds were dried and grinded. Extraction from the seeds was carried out by maceration with $50 \%$ ethanol at room temperature for 7 days and the extract was dried under vacuum by rotary evaporator followed by freeze drier [19]. The extract was poured into a special container and stored in a refrigerator.

\subsection{Analysis of the extract}

Analysis of the extract was carried out by HPLC and the results were published in our previous article [20]. As mentioned in our previous study, the presence of Deoxypodophyllotoxin in the extract was measured by HPLC. For this purpose, Phenomenex Gemini C18 column was (3 $\mathrm{lm}, 0 Æ 3.150 \mathrm{~mm}$ ) (Torrance, CA, USA) utilized and 0.02 molar ammonium acetate was used in the mobile 
phase and $\mathrm{PH}$ set at 5.5 using phosphate buffer and eluted with acetonitrile with a flow rate of $1 \mathrm{ml} / \mathrm{min}$ for $30 \mathrm{~min}$ at a temperature of $30{ }^{\circ} \mathrm{C}$. The results confirmed the presence of Deoxypodophyllotoxin in the JCS extract as seen in Fig. 1 with the peak at the same point in both the standard substance and the extract [20].

\subsection{Flavonoids and total phenolic content determination}

The aluminum chloride colorimetric method [21] and Folin-Ciocalteu assay method were used to measure flavonoids and the total phenolic content, respectively [22, 23].

\subsection{Animals and experimental design}

Male adult Wistar rats weighing between 230 and $280 \mathrm{~g}$ were taken from the Institute for Laboratory Animal Research of Mazandaran University of Medical Science and were kept under standard conditions (12-h lightdark cycle and room temperature) in clean cages for 3 days and the animals had free access to standard food and water.

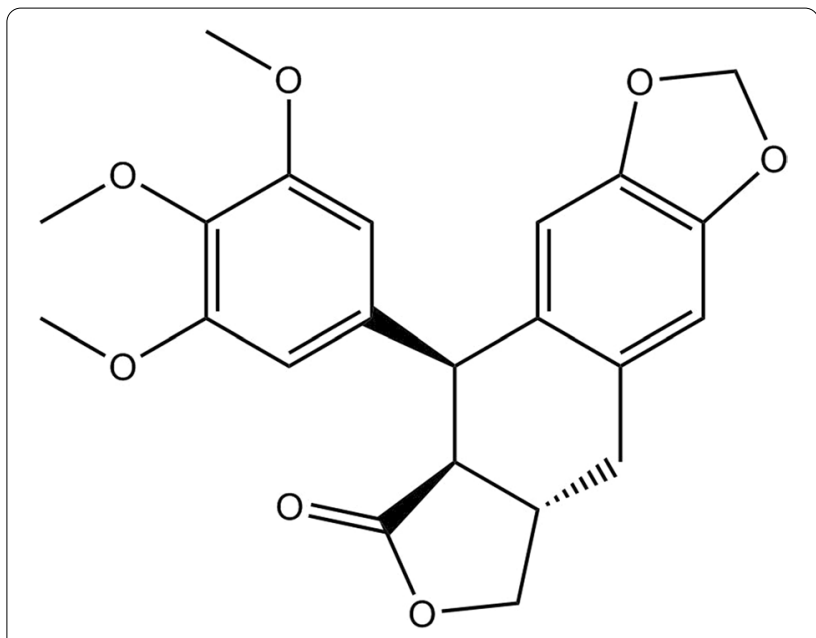

Fig. 1 Structure of deoxypodophyllotoxin
This study was conducted in accordance with the principles of the Association for the Protection of Animal Rights with the ethical code IR.MAZUMS. REC.1398.2740 and animal rights were respected.

A total of 30 male rats were divided into 5 groups ( $N=6$ each cage) and treated according to the following protocol: 24 rats received a daily dose of $25 \mathrm{mg} / \mathrm{kg}$ body weight testosterone enanthate (TE) for 28 days; TE was loaded with corn oil and given intramuscularly. This procedure causes BPH based on similar studies [24]. 6 rats did not receive TE and just received IM corn oil injection as the normal group (vehicle). Standard medicine group received intramuscular $\mathrm{TE}$ and $10 \mathrm{mg} / \mathrm{kg}$ body weight finasteride through daily gavage [25]. The design of the experimental procedure used in the study is shown in Table 1.

\subsection{Evaluation of biochemical parameters}

The rats were treated for 28 days and their weights were measured on the first and 28th day. At the end of the experiment, they were anesthetized. The prostate glands were removed and weighed, half of the group's prostates were sent to the toxicology laboratory for biochemical tests including malondialdehyde (MDA), glutathione (GSH) and protein carbonyl (PCO) groups, and the other halves were placed in containers with $10 \%$ formalin and stained with hematoxylin and eosin for histopathological examination.

\subsection{Malondialdehyde}

Malondialdehyde (MDA) level is an indicator of lipid peroxidation, and was measured according to the Satoh method in the tissue [26]. Method of measuring Malondialdehyde was based on reaction with thiobarbituric acid (from Merck company) and extraction with normal butanol, absorption measured by spectrophotometric method and compared with the standard curve. Malondialdehyde content was measured using a spectrophotometer at $532 \mathrm{~nm}$ and butanol was used as blank.

Table 1 Design of experimental procedure

\begin{tabular}{llll}
\hline Groups & Group category & $\begin{array}{l}\text { Muscle injection of 25 mg/kg of TE } \\
\text { in corn oil }\end{array}$ & Treatment according to kg weight \\
\hline Group 1 & Normal group (vehicle) & - & Distilled water gavage \\
Group 2 & Disease group & + & Distilled water gavage \\
Group 3 & Standard medicine group & + & $10 \mathrm{mg} / \mathrm{kg} \mathrm{finasteride} \mathrm{gavage}$ \\
Group 4 & Group treated with $300 \mathrm{mg} / \mathrm{kg} \mathrm{JCS} \mathrm{extract}$ & + & $300 \mathrm{mg} / \mathrm{kg} \mathrm{JCS} \mathrm{extract}$ \\
Group 5 & Group treated with 600 mg/kg JCS extract & + & $600 \mathrm{mg} / \mathrm{kg} \mathrm{JCS} \mathrm{extract}$ \\
\hline
\end{tabular}




\subsection{Glutathione (GSH)}

Glutathione (GSH) is a master antioxidant and was measured according to Sedlak \& Lindsay's method [27, 28]. For measuring the GSH level, the tissue was homogenized and the supernatant was separated and mixed with $0.02 \%$ Tris buffer containing $0.02 \mathrm{mM}$ EDTA $(\mathrm{pH}=8.9 \mathrm{f})$ and 0.01 molar DTNB [5,5'-dithiobis-(2-nitrobenzoic acid)] and finally absorbed at $412 \mathrm{~nm}$.

\subsection{Protein carbonyl (PCO)}

Protein carbonyl groups, as the biomarkers of oxidative stress, were measured according to Levine et al's method. The optical absorption of the hydrazone was induced by the reaction between 2- and 4-dinitrophenylhydrazine (DNPH) and carbonyls were measured using spectrophotometry at $405 \mathrm{~nm}$ [29].

\subsection{PSA content}

After anesthetizing the rats, blood samples were collected from their hearts and sent to an associate laboratory to evaluate free prostate specific antigen (PSA) in the blood using the PSA ELISA kit [25].

\subsection{Body weight and prostate weight}

Body weights were measured in the beginning and the end of the experiment. Also, prostate weights were measured after anesthetizing the animals using a ketamineXylazine mixture with a dose of $0.15 \mathrm{ml} / 100 \mathrm{gm}$ per body weight via Intraperitoneal injection and removing prostate glands.

Prostate index is a formula that can be used to obtain the prostate weight to body weight ratio. When comparing each group with normal and disease groups, any changes in this index indicate the percentage of inhibition of the progression of the disease (2). Using the two measured weights and these formulas, prostate index (1), inhibition prostate weight and inhibition prostate index (2) are calculated.

$$
\begin{aligned}
& \text { Prostate index }=\frac{\text { Prostate weight }}{\text { Body weights }} \quad \text { (1) } \begin{array}{l}
3.2 \text { Body weight } \\
\text { There was no significant }
\end{array} \\
& \text { Percentage of inhibition }=100-\left[\frac{\text { Treatment group }- \text { Negative control }}{\text { Disease group }- \text { Negative control }} \times 100\right]
\end{aligned}
$$$$
\text { There was no significant difference between group's }
$$

\section{Results}

\subsection{Phenol and flavonoid contents of the extracts}

The flavonoid amount in the JCS extract was calculated using standard curve equation of quercetin $\left(y=0.0026 x+0.0113 R^{2}=0.9986\right)$, expressed as quercetin equivalents and measured to be $0.435(\mathrm{mg} / 100 \mathrm{~g}$ of dry extracts).

In addition, the phenol content was measured using the Folin-Ciocalteu assay method with the standard curve equation $\left(y=0.0076 x+0.0036 R^{2}=0.9992\right)$ and expressed as gallic acid equivalents and was measured to be 0.648 ( $\mathrm{mg} / 100 \mathrm{~g}$ of dry extracts).

\subsection{Histopathological examination}

To investigate morphological changes, the tissue was cut into 4- $\mu \mathrm{m}$ sections using a rotary microtome, stained with eosin and hematoxylin and was observed under a $40 \times$ microscope [30]. weights in the beginning and the end of the experiment. All groups showed weight gain because of receiving intramuscular corn oil with the exception of the disease group which had an $11 \%$ weight loss. 


\subsection{Prostate weight}

Because it is impossible to reach the initial prostate weight of the groups, it was compared based on the weight of the normal group (vehicle group) at the end of the study. Testosterone administration significantly increased the prostate weight in rats compared to the normal group. The prostate weights of the groups treated with JCS extracts (300 mg/ $\mathrm{kg}$ and $600 \mathrm{mg} / \mathrm{kg}$ ) were decreased dose-dependently compared to the disease control group. A similar effect was observed in the standard medicine group. The prostate index, inhibition prostate weight and inhibition prostate index are shown in Table 2.

\subsection{Evaluation of biochemical parameters}

MDA estimation results indicated a significant increase in MDA level in the TE group compared to the control group as the lipid peroxidation index $(p<0.001)$ and a decrease in finasteride and JCS 300, $600 \mathrm{mg} / \mathrm{kg}$ $(p<0.01, p<0.01, p<0.01$, respectively) groups compared to the TE group (Fig. 2a).

The results showed significant decrease in GSH $(p<0.001)$ level in the TE group compared to the control group. However, finasteride group and JCS extract with doses of $300 \mathrm{mg} / \mathrm{kg}$ and $600 \mathrm{mg} / \mathrm{kg}$ showed an increase in GSH level $(p<0.01, p<0.05, p<0.01$, respectively) compared to the disease group (Fig. 2b).
Protein carbonyl group examination results showed significant increase in the disease group $(p<0.001)$ compared to the control group and a decrease in standard medicine group and JCS extract with doses of 300 and $600 \mathrm{mg} / \mathrm{kg}(p<0.05, p<0.05, p<0.001$, respectively) compared to the disease group (Fig. 2c).

\subsection{PSA}

In the disease group, as mentioned above, PSA level was elevated $(p<0.05)$ compared to the normal control group. In groups of JCS extract with doses of 300 and $600 \mathrm{mg} /$ $\mathrm{kg}$, PSA was observed in normal range and differed from the disease group significantly $(p<0.05)$. The standard medicine group also showed a higher PSA in comparison to the disease group (Fig. 3).

\subsection{Histopathological examination}

Based on histopathological results, progression of stromal proliferation, abnormal acinar fold, hypertrophy and hemorrhage was observed in th disease group compared with the normal control group. The group treated with $300 \mathrm{mg} / \mathrm{kg}$ JCS extract showed slight glandular hemorrhage, hyperplasia and acinar lipid fold changes. Standard medicine group showed slight histological changes. In the $600 \mathrm{mg} / \mathrm{kg}$ JCS extract group, there were no histological changes compared to the normal control group (Fig. 4).

Table 2 Weight and appendix parameters

\begin{tabular}{|c|c|c|c|c|c|c|}
\hline Groups & Initial Body weight (g) & Final body weight (g) & Prostate weight (mg) & $\begin{array}{l}\% \text { inhibition } \\
\text { Prostate weight }\end{array}$ & Prostate index $\times 10^{-3}$ & $\begin{array}{l}\text { \% inhibition } \\
\text { prostate } \\
\text { index }\end{array}$ \\
\hline $\begin{array}{l}\text { Normal group } \\
\text { (vehicle) }\end{array}$ & $260 \pm 8.99$ & $300 \pm 3.32$ & $259 \pm 4.05$ & - & $0.866 \pm 0.12$ & - \\
\hline $\begin{array}{l}\text { Disease group (IM TE } \\
\text { injection) }\end{array}$ & $248 \pm 2.93^{*}$ & $219 \pm 4.25^{* * *}$ & $359 \pm 5.91^{* * *}$ & - & $1.6419 \pm 0.01^{* * *}$ & - \\
\hline $\begin{array}{l}\text { Standard medicine } \\
\text { group (TE + finas- } \\
\text { teride) }\end{array}$ & $239 \pm 4.96$ & $260 \pm 6.36^{\# \# \#}$ & $293 \pm 4.30^{\# \# \#}$ & 66.5 & $1.1127^{\# \# \#} \pm 0.01$ & 68.2033 \\
\hline $\begin{array}{l}\text { Group treated } \\
\text { with } 300 \mathrm{mg} / \\
\text { kg JCS extract } \\
(\mathrm{TE}+300 \mathrm{mg} / \mathrm{kg} \\
\text { JCS })\end{array}$ & $237 \pm 5.87^{\#}$ & $273 \pm 7.12^{\# \# \#}$ & $320 \pm 2.30^{\# \# \#}$ & 39.4 & $1.1173^{\# \# \#} \pm 0.01$ & 67.6038 \\
\hline $\begin{array}{l}\text { Group treated } \\
\text { with } 600 \mathrm{mg} / \\
\mathrm{kg} J C S \text { extract } \\
\text { (TE + } 600 \mathrm{mg} / \mathrm{kg} \\
\text { JCS) }\end{array}$ & $267 \pm 1.01^{\#}$ & $280 \pm 2.26^{\# \# \#}$ & $299 \pm 5.26^{\# \# \#}$ & 60.3 & $1.1193^{\# \# \#} \pm 0.02$ & 67.3522 \\
\hline
\end{tabular}

Body weight, prostate weight and prostatic index in the examination groups were as follows: normal group (vehicle), disease group, standard medicine group, groups treated with $300 \mathrm{mg} / \mathrm{kg}$ and $600 \mathrm{mg} / \mathrm{kg}$ JCS extract for 28 days

$T E$ testosterone enanthate, JCS Juniperus communis

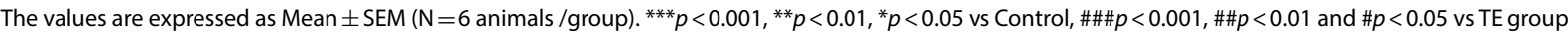



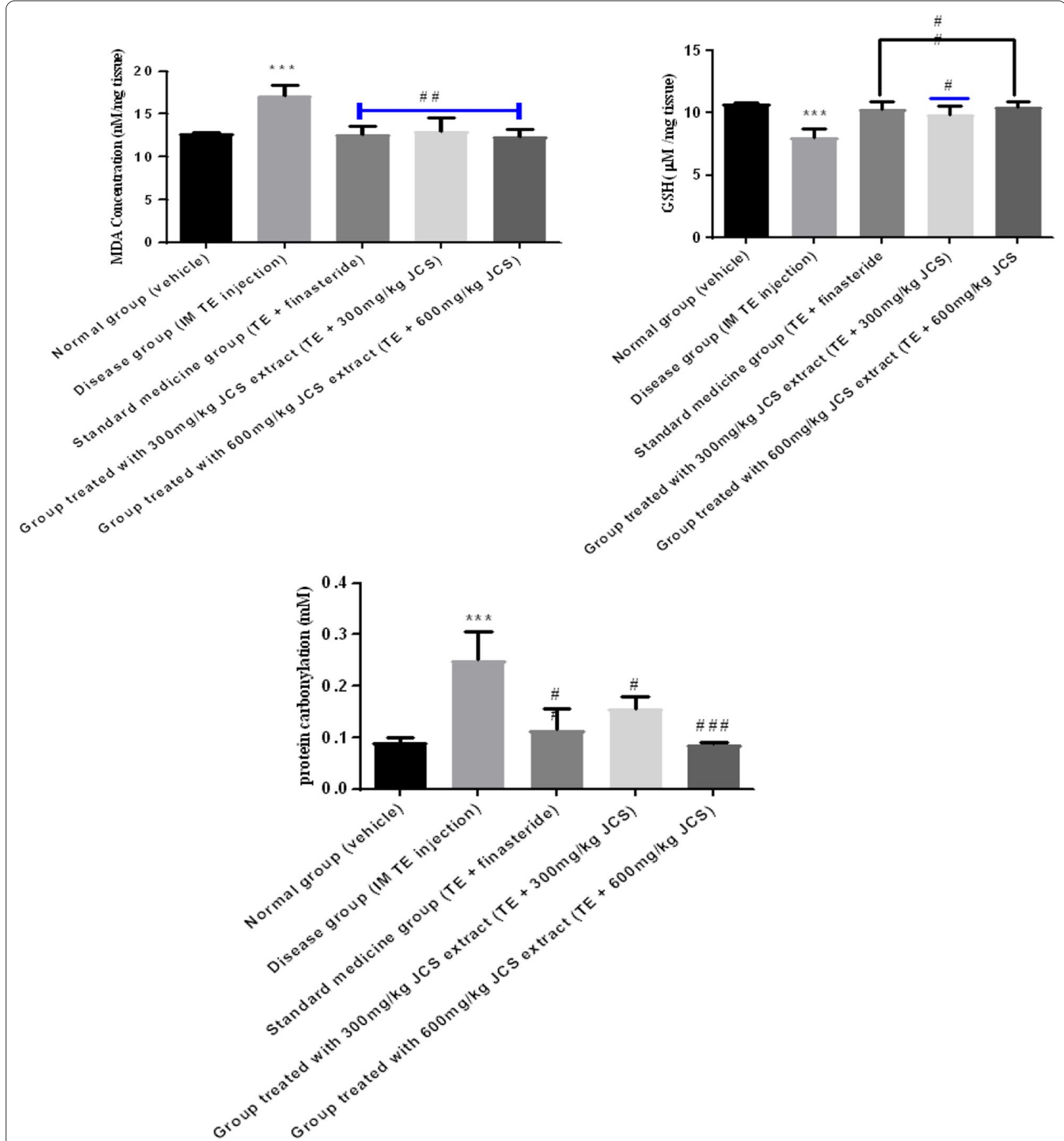

Fig. 2 GSH, MDA \& PCO levels of prostate tissue. The values are expressed as Mean \pm SEM ( $N=6$ animals/group). ${ }^{* *} p<0.001$ and ${ }^{* *} p<0.01$ versus Control, \#\#\# <0.001, \#\#p<0.01 and \#p<0.05 versus testosterone

\subsection{Acute toxicity test}

In the group with a dose of $2000 \mathrm{mg} / \mathrm{kg} \mathrm{JCS}$ extract, no mortality and morbidity were observed during the 14-day testing period. The results of biochemical studies showed that the extract significantly increases the level of liver enzymes (Table 3). Therefore, the therapeutic doses (300 and $600 \mathrm{mg} / \mathrm{kg}$ body weight) used in this study should be administered with caution. 


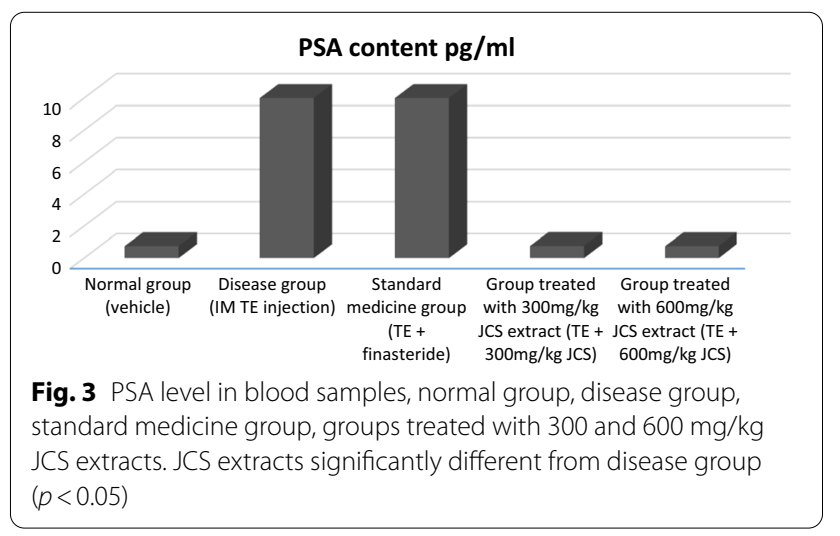

\section{Discussion}

Prostatic hyperplasia is a high-prevalence urinary tract disease in elderly men [32]. Testosterone induces hyperplasia in simple epithelial cells by causing frequent inflammation of the epithelial cells over time, resulting in frequent urination and poor urine flow and emergency urination [32].

The present study investigated the potential efficacy of JCS extract by performing muscle injection of TE for 28 days. Prostatic hyperplasia occurs in animals during this period, and it is obtained from the index of prostate weight to body weight and histopathological results, all of which were observed in Dwarakanath et al's results as well [24].

5-Alpha reductase converts androgens to estrogen and dihydrotestosterone (DTH). Estrogen has a key role in the growth and increase in prostate cells through oxidative function and after being combined with DTH, it can cause an additional effect on BPH [8]. Finasteride treatment reduces 5 -alpha reductase function and decreases DTH blood level and, thereby, reduces oxidative stress and preserves the body's antioxidants. Evidence also suggests that prostate zinc levels are increased in BPH [33].

Apart from the function of the 5-alpha reductase enzyme, oxidative stress plays an important role in the development of prostatic hyperplasia [34]. Oxidative stress is caused by a disruption in the balance between antioxidants and reactive oxygen species (ROS) which increases the active radicals and decreases the body's immune system functionality [35]. In the present study, oxidative stress was observed in rats treated with testosterone in the disease group, evidenced by an increased level of MDA and PCO, but decreased levels of GSH.

Endogenous testosterone is converted to DTH in prostate stromal cells. This is far more potent than testosterone and causes changes in androgen receptors on the surface of epithelial cells, which causes mitochondrial leakage and free radical production due to altering the DNA transcription. Lipid peroxidation is an important marker of oxidative stress [36]. Peroxides promote the progression of cells to cancer. Glutathione acts as a cell protector by reducing the level of free radicals, and superoxide dismutase (SOD) is an enzyme that has an antioxidant role. Therefore, by lowering the level of this enzyme, the body cells are more likely to be damaged by active radicals [37]. High levels of nitrate radicals have also been found in prostatic hyperplasia which confirms the important role of antioxidants in the fight against the disease [38].

Various studies have investigated many herbal treatments for BPH in which, similar to the present study, the duration of the experimental procedure was about 4 weeks [30, 39, 40]. In Sik Shin et al's study, Yukmijihwang-tang, a traditional Korean herbal formula, was evaluated for the treatment of BPH in Wistar rats. Daily doses of testosterone propionate were administered to induce the disease [39]. Testosterone propionate was slow-release and had a short half-life form of testosterone in comparison with testosterone enanthate which was used in the present study. Another study examined the effect of curcumin on testosterone-induced BPH. Similar to other studies, rats were selected for this treatment. They were castrated and then the procedure of the treatment with subcutaneous testosterone was performed. Curcumin showed an inhibition in the development of BPH [30].

Finasteride was used as the standard medicine in all related research. Lee et al. used $5 \mathrm{mg} / \mathrm{kg}$ finasteride as the standard medicine [41]. Many researches used $10 \mathrm{mg} / \mathrm{kg}$ finasteride [42-44] and so does the present study, but we found that giving $10 \mathrm{mg} / \mathrm{kg}$ finasteride was not sufficient for treating BPH because an increase in the PSA level was observed in this group (Fig. 3). This fact was also concluded from histopathological results which showed slight morphological changes (Fig. 4).

Limonene was evaluated for the treatment of testosterone enanthate induced BPH. The administered dose of TE was $25 \mathrm{mg}$ per body weight per day for 21 days, and limonene showed its efficacy in preventing the disease [24]. In the present study, we also used TE as a $\mathrm{BPH}$ inducer with the same dose explained in the limonene study.

Juniperus communis $\mathrm{L}$. is an evergreen tree or shrub and was traditionally used for urinary retention and intermittency urination [20, 45]. Many studies evaluate the abortifacient effects of Juniperus communis. One examination of JCS extract on female rats using this extract with a dose of 300 and $500 \mathrm{mg} / \mathrm{kg}$ body weight in days 1-7 of pregnancy led to an increase in the rate of 


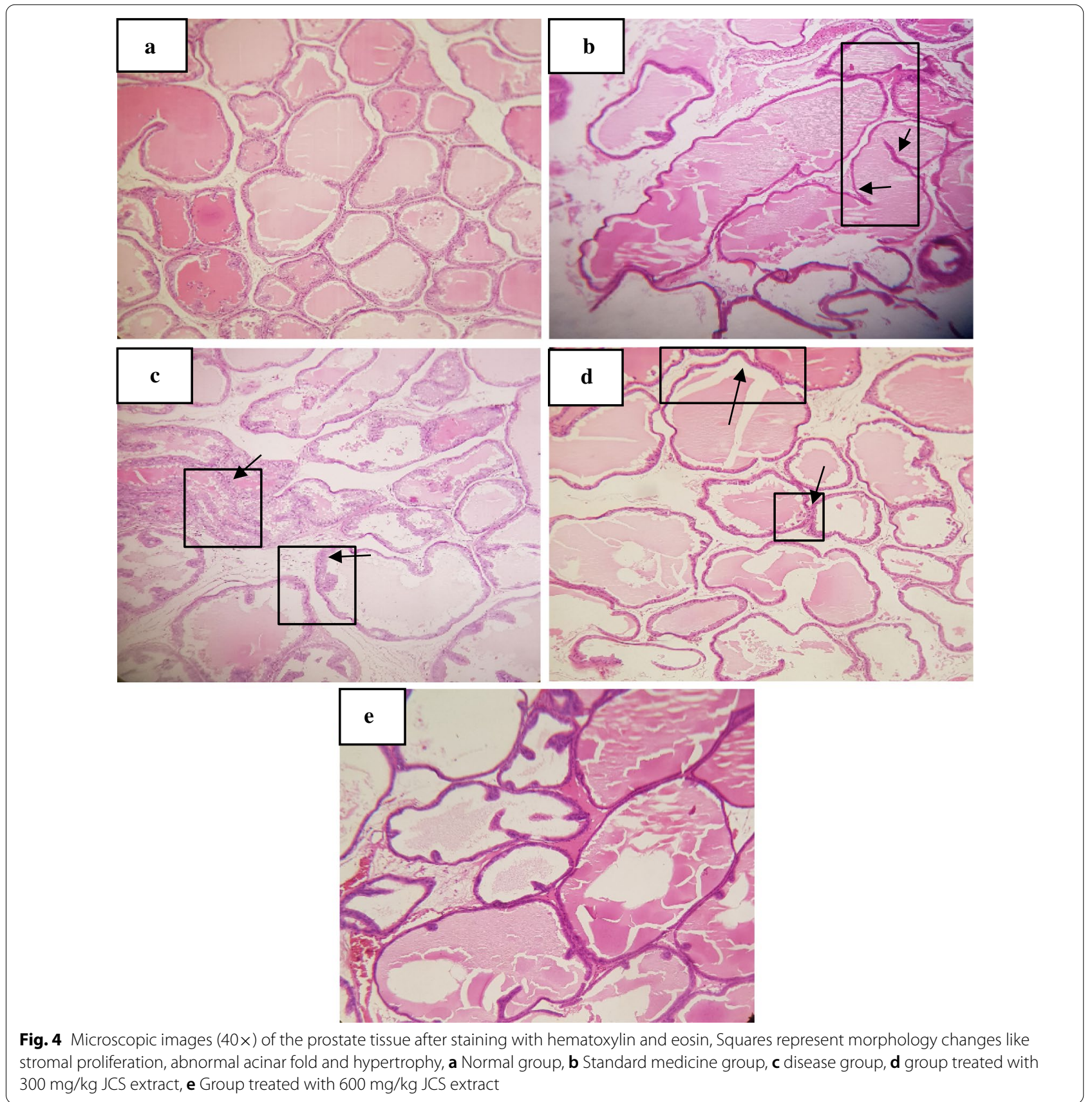

abortifacients [18]. Furthermore, Juniperus was examined in many studies to evaluate how it affects sex hormones. One of the studies evaluated the JCS extract on estrogen receptor-positive breast cancer cells in vitro and the results showed that this extract was able to bind estrogen receptors [46]. Previous research on the plant has shown that it is capable of inhibiting cancer cell lines in the prostate tissue [20].

Juniperus communis contains two important compounds: phenolic components and essential oils. One of these phenolic compounds is lignan [47]. Dietary intake of lignans influences sex hormone-dependent cancer incidence by modulating the hormonal environment [48]. Podophyllotoxin is a natural compound related to lignans and has antimitotic activity $[49,50]$. It is highly efficient in inhibiting the growth of cancer calls and leads to the production of valuable anticancer agents like etoposide and teniposide [51].

With these two active compounds and considering the in vitro and in vivo evidence and history usage of JCS in 
Table 3 Liver enzymes changes in the acute toxicity test

\begin{tabular}{lllll}
\hline Groups & ALP & LDH & SGOT(AST) & SGPT(ALT) \\
\hline 1 & 253 & 1967 & 317 & 58 \\
2 & 308 & 1692 & 251 & 63 \\
3 & 517 & 1103 & 150 & 44 \\
4 & 679 & 2386 & 326 & 82 \\
$\begin{array}{l}\text { Reference } \\
\text { value }\end{array}$ & $80-306(\mathrm{U} / \mathrm{L})$ & $138-280(\mathrm{U} / \mathrm{L})$ & $5-40(\mathrm{U} / \mathrm{L})$ & $5-40(\mathrm{U} / \mathrm{L})$ \\
\hline
\end{tabular}

Female (repeated groups 1 and 2) and male (repeated groups 3 and 4) rats received $2000 \mathrm{mg} / \mathrm{kg} \mathrm{JCS}$ extract

$A L P$ alkaline phosphatase, $L D H$ lactate dehydrogenase, $S G O T$ (AST) aspartate aminotransferase; SGPT (ALT) alanine aminotransferase

urinary retention and intermittency urination, this study was designed to examine the effect of JCS extract on a sex hormone related disease, the BPH (Additional file 1: Fig. S1).

In this study, a significant increase was observed in prostate weight in the disease group compared with the normal group which was due to a growth in the quantity of cellular numbers in the prostate tissue. This result is in line with the findings of Wang et al.s study [52]. Histopathological results showed proliferation of stromal cells in TE group. Treatment with a dose of $300 \mathrm{mg} / \mathrm{kg}$ JCS extract showed a partial hyperplasia in glandular cells while in the group where the administered dose was $600 \mathrm{mg} / \mathrm{kg}$, virtually no hyperplasia was observed (Additional file 1: Fig. S2).

How this extract works is complicated, but its antioxidant capacity with rich phenol and flavonoid contents and also its lignans such as Deoxypodophyllotoxin, which have anticancer characteristics, can be the possible therapeutic mechanisms of this extract. However, further study needs to find out more about the mechanism. This study examined the compounds of the extract (phenolic compound, flavonoids, terpenoids) and found their therapeutic effects on BPH. It should be mentioned that due to some difficulties such as inaccessibility to the relevant accessory, the cell cycling procedure of the extract and the active ingredient, the information of this study was limited to the efficacy of the extract in in vivo conditions.

\section{Conclusion}

Oral administration of JCS extract is able to prevent testosterone-induced hyperplasia in rats. The inhibitory effect of JCS extract was probably due to the regulation of inflammatory responses by reducing oxidative stress and anti-proliferative effect according to biochemical biomarker results which showed a decrease in MDA and PCO and an increase in GSH in JCS groups. This study suggests evaluating the toxicity of JCS active components on $\mathrm{BPH}$ for future studies.

\section{Abbreviations}

ALP: alkaline phosphatase; AST: aspartate aminotransferase; BPH: benign prostatic hyperplasia; DNPH: 2,4-dinitrophenylhydrazine; DTH: dihydrotestosterone; GSH: glutathione; JCS: Juniperus communis L. seed; LDH: lactate dehydrogenase; MDA: malondialdehyde; OECD: Organization for Economic Co-operation and Development; PCO: protein carbonyl; PSA: prostate specific antigen; SOD: superoxide dismutase; TE: testosterone enanthate.

\section{Supplementary Information}

The online version contains supplementary material available at https://doi. org/10.1186/s12301-021-00137-x.

Additional file 1. Determination of Deoxypodophyllotoxin by using HPLC method.

\section{Acknowledgements}

The authors would like to express thanks to those individuals who provided help during the research especially Mr. Ebrahim Moradi from animal laboratory, animal research institute.

\section{Authors' contributions}

All authors have read and approved the manuscript", and ensure that this is the case. Conceptualization: FA; Data curation: MS; Formal analysis: DA; Methodology: ZM; Methodology: SAS; Project administration: FA; Resources: ABN; Supervision: MA; Validation: LV; Visualization: FA; Writing-original draft: FA; Writing-review and editing: KM.

\section{Funding}

This work has no funding. The work was supported by the Research Center of Mazandaran University of Medical Sciences, Sari, Iran.

\section{Availability of data and materials}

All material such as rats and Finasteride, Testosterone enanthate and ethanol for extracting of Juniperus communis L. provided my medical university of

Mazandaran and all data obtained from the laboratory of Mazandaran university of medical science such as pathology, serology and toxicology laboratory.

\section{Ethics approval and consent to participate}

This study was approved by the Ethics Committee of MAZUMS, Sari, Iran. The study was conducted in accordance with the principles of the Association for the Protection of Animal Rights with the ethical code IR.MAZUMS. REC.1398.2740 and animal rights were respected.

\section{Consent for publication}

Not applicable.

\section{Competing interests}

The authors declare that they have no competing interests.

\section{Author details}

${ }^{1}$ Department of Pharmacognosy, Faculty of Pharmacy, Mazandaran University of Medical Sciences, 17th Kilometer of Farah Abad Street, 47178-43611 Sari, Iran. ${ }^{2}$ New Delhi, India. ${ }^{3}$ Department of Toxicology, Faculty of Pharmacy, Mazandaran University of Medical Sciences, 17th Kilometer of Farah Abad Street, Sari, Iran. ${ }^{4}$ Department of Pathology, Faculty of Medicine, Mazandaran University of Medical Sciences, Imam Khomeini Hospital, Sari, Iran. ${ }^{5}$ Department of Urology, Faculty of Medicine, Mazandaran University of Medical Sciences, Imam Khomeini Hospital, Sari, Iran. ${ }^{6}$ Student Research Committee, Faculty of Pharmacy, Mazandaran University of Medical Sciences, 17th Kilometer of Farah Abad Street, Sari, Iran. ${ }^{7}$ Department of Chemistry, Damghan University of Sciences, Saadi Square, Damghan, Iran.

Received: 3 September 2020 Accepted: 4 February 2021

Published online: 15 March 2021 


\section{References}

1. Rohrmann S, Katzke V, Kaaks R (2016) Prevalence and progression of lower urinary tract symptoms in an aging population. Urology 95:158-163

2. Iscaife A, Anjos G, Barbosa Neto C, Nahas WC, Srougi M, Antunes AA (2018) The role of bladder diverticula in the prevalence of acute urinary retention in patients with BPH who are candidates to surgery. Int Braz J Urol 44(4):765-770

3. Loughlin KR (ed) (2016) The testosterone conundrum: the putative relationship between testosterone levels and prostate cancer. Urologic oncology: seminars and original investigations. Elsevier

4. Heber D (2002) Prostate enlargement: The canary in the coal mine? Oxford University Press, Oxford

5. DiBello JR, loannou C, Rees J, Challacombe B, Maskell J, Choudhury N et al (2016) Prevalence of metabolic syndrome and its components among men with and without clinical benign prostatic hyperplasia: a large, cross-sectional, UK epidemiological study. BJU Int 117(5):801-808

6. Krieg M, Nass R, Tunn S (1993) Effect of aging on endogenous level of 5 alpha-dihydrotestosterone, testosterone, estradiol, and estrone in epithelium and stroma of normal and hyperplastic human prostate. J Clin Endocrinol Metab 77(2):375-381

7. Ho CK, Habib FK (2011) Estrogen and androgen signaling in the pathogenesis of BPH. Nat Rev Urol 8(1):29

8. Mirone V, La Rocca R, Franco M, Venturino L (2018) Pathologic triggers related to LUTS and BPH. In: Morgia G, Russo GI (eds) Lower urinary tract symptoms and benign prostatic hyperplasia. Elsevier, Amsterdam, pp 15-29

9. Bartsch G, Rittmaster R, Klocker H (2002) Dihydrotestosteron und die Rolle der $5 a$-Reduktasehemmer bei der benignen Prostatahyperplasie. Der Urologe A 41(5):412-424

10. Hoffman RM (2018) Clinical usefulness of the histoculture drug response assay for prostate cancer and benign prostate hypertrophy (BPH). In: Hoffman RM (ed) 3D sponge-matrix histoculture. Berlin, Springer, pp 101-107

11. Wang-Michelitsch J, Michelitsch TM (2015) Tissue fibrosis: a principal proof for the central role of Misrepair in aging. arXiv preprint https:// arxiv.org/abs/1505.01376

12. Thorpe A, Neal D (2003) Benign prostatic hyperplasia. Lancet 361(9366):1359-1367

13. Pinggera G-M, Frauscher $F$ (2016) Do we really need herbal medicine in LUTS/BPH treatment in the 21st century? Expert Opin Drug Safe 15(12):1573-1575

14. Foudil-Cherif $Y$, Yassaa N (2012) Enantiomeric and non-enantiomeric monoterpenes of Juniperus communis L. and Juniperus oxycedrus needles and berries determined by HS-SPME and enantioselective GC/MS. Food Chem 135(3):1796-1800

15. Lantto TA, Laakso I, Dorman H, Mauriala T, Hiltunen R, Kõks S et al (2016) Cellular stress and p53-associated apoptosis by Juniperus communis L. Berry extract treatment in the human SH-SY5Y neuroblastoma cells. Int J Mol Sci 17(7):1113

16. Barjaktarović B, Sovilj M, Knez Ž (2005) Chemical composition of Juniperus communis $\mathrm{L}$. fruits supercritical $\mathrm{CO}_{2}$ extracts: dependence on pressure and extraction time. J Agric Food Chem 53(7):2630-2636

17. Höferl M, Stoilova I, Schmidt E, Wanner J, Jirovetz L, Trifonova D et al (2014) Chemical composition and antioxidant properties of Juniper berry (Juniperus communis L.) essential oil. Action of the essential oil on the antioxidant protection of Saccharomyces cerevisiae model organism. Antioxidants 3(1):81-98

18. Agrawal O, Bharadwaj S, Mathur R (1980) Antifertility effects of fruits of Juniperus communis. Planta Med 40(S1):98-101

19. McCartan SA, Gosling PG (2013) Guidelines for seed collection and stratification of common juniper (Juniperus communis L.). Tree Planters' Notes 56(1):24-29

20. Mahdavi M, Azadbakht M, Vahdati A, Shokrzadeh M, Farhadi A (2019) Anticancer effects of deoxypodophyllotoxin and Juniperus communis L. on prostate cancer cell lines. J Mazandaran Univ Med Sci 29(177):13-29

21. Chang C-C, Yang M-H, Wen H-M, Chern J-C (2002) Estimation of total flavonoid content in propolis by two complementary colorimetric methods. J Food Drug Ana 10(3):178-182
22. Nikolova M (2011) Screening of radical scavenging activity and polyphenol content of Bulgarian plant species. Pharmacogn Res 3(4):256

23. Nićiforović N, Mihailović V, Mašković P, Solujić S, Stojković A Muratspahić DP (2010) Antioxidant activity of selected plant species; potential new sources of natural antioxidants. Food Chem Toxicol 48(11):3125-3130

24. Dwarakanath V, Kumar N, Kumar RA, Goud BJ (2017) Defensive action of limonene on te induced BPH in male wistar rats. Int J Adv Res Eng Appl Sci 6(10):8-23

25. Akanni OO, Abiola OJ, Adaramoye OA (2017) Methyl jasmonate ameliorates testosterone propionate-induced prostatic hyperplasia in castrated wistar rats. Phytother Res 31(4):647-656

26. Khoubnasabjafari M, Ansarin K, Jouyban A (2016) Critical review of malondialdehyde analysis in biological samples. Curr Pharm Anal 12(1):4-17

27. Nalbantsoy A, Nesil T, Erden S, Çalış İ, Bedir E (2011) Adjuvant effects of Astragalus saponins macrophyllosaponin B and astragaloside VII. J Ethnopharmacol 134(3):897-903

28. Sedlak J, Lindsay RH (1968) Estimation of total, protein-bound, and nonprotein sulfhydryl groups in tissue with Ellman's reagent. Anal Biochem 25:192-205

29. Levine RL, Garland D, Oliver CN, Amici A, Climent I, Lenz A-G et al (1990) Determination of carbonyl content in oxidatively modified proteins. Methods Enzymol 186:464-478

30. Kim SK, Seok H, Park HJ, Jeon HS, Kang SW, Lee B-C et al (2015) Inhibitory effect of curcumin on testosterone induced benign prostatic hyperplasia rat model. BMC Complement Altern Med 15(1):380

31. Wolff FR, Broering MF, Jurcevic JD, Zermiani T, Bramorski A, de Carvalho VJ et al (2019) Safety assessment of Piper cernuum Vell. (Piperaceae) leaves extract: acute, sub-acute toxicity and genotoxicity studies. J Ethnopharmacol 230:109-116

32. Speakman MJ, Cheng X (2014) Management of the complications of BPH/BOO. Indian J Urol IJU: J Urol Soc India 30(2):208

33. Gonzales C, Leiva-Revilla J, Rubio J, Gasco M, Gonzales G (2012) Effect of red maca (Lepidium meyenii) on prostate zinc levels in rats with testosterone-induced prostatic hyperplasia. Andrologia 44:362-369

34. Gupta-Elera G, Garrett AR, Robison RA, O'Neill KL (2012) The role of oxidative stress in prostate cancer. Eur J Cancer Prev 21(2):155-162

35. Khandrika L, Kumar B, Koul S, Maroni P, Koul HK (2009) Oxidative stress in prostate cancer. Cancer Lett 282(2):125-136

36. Kosova F, Temeltaş G, Arı Z, Lekili M (2014) Possible relations between oxidative damage and apoptosis in benign prostate hyperplasia and prostate cancer patients. Tumor Biol 35(5):4295-4299

37. Ahmed Amar SA, Eryilmaz R, Demir H, Aykan S, Demir C (2019) Determination of oxidative stress levels and some antioxidant enzyme activities in prostate cancer. Aging Male 22(3):198-206

38. Arsova-Sarafinovska Z, Eken A, Matevska N, Erdem O, Sayal A, Savaser A et al (2009) Increased oxidative/nitrosative stress and decreased antioxidant enzyme activities in prostate cancer. Clin Biochem 42(12):1228-1235

39. Shin IS, Lee MY, Ha HK, Seo CS, Shin H-K (2012) Inhibitory effect of Yukmijihwang-tang, a traditional herbal formula against testosteroneinduced benign prostatic hyperplasia in rats. BMC Complement Altern Med 12(1):48

40. Park E, Lee $M-Y$, Jeon $W-Y$, Lee N, Seo C-S, Shin H-K (2016) Inhibitory effect of yongdamsagan-tang water extract, a traditional herbal formula, on testosterone-induced benign prostatic hyperplasia in rats. Evidence Based Complement Altern Med 2016:1-8

41. Lee G, Shin J, Choi H, Jo A, Pan S, Bae D et al (2017) Cynanchum wilfordii ameliorates testosterone-induced benign prostatic hyperplasia by regulating 5 a-reductase and androgen receptor activities in a rat model. Nutrients 9(10):1070

42. Liu J, Fang T, Li M, Song Y, Li J, Xue Z et al (2019) Pao pereira extract attenuates testosterone-induced Benign prostatic hyperplasia in rats by inhibiting 5a-reductase. Sci Rep 9(1):1-10

43. Talpur N, Echard B, Bagchi D, Bagchi M, Preuss HG (2003) Comparison of Saw Palmetto (extract and whole berry) and Cernitin on prostate growth in rats. Mol Cell Biochem 250(1-2):21-26

44. Adaramoye OA, Oladipo TD, Akanni OO, Abiola OJ (2019) Hexane fraction of Annona muricata (Sour sop) seed ameliorates 
testosterone-induced benign prostatic hyperplasia in rats. Biomed Pharmacother 111:403-413

45. Avicenna (2008) Avicenna Canon of Medicine. Ministry of Health, Treatment and Medical Training Publication. 2:682-63.

46. Zava DT, Dollbaum CM, Blen M (1998) Estrogen and progestin bioactivity of foods, herbs, and spices. Proc Soc Exp Biol Med 217(3):369-378

47. Sakar MK, Easr N, Er D, Del Olmo E, San Feliciano A (2002) Desoxypodophyllotoxin and diterpenoids from Juniperus nana Willd. berries. ACTA Pharm Sci 44(3):213-219

48. Shultz TD, Bonorden WR, Seaman WR (1991) Effect of short-term flaxseed consumption on lignan and sex hormone metabolism in men Nutr Res 11(10):1089-1100

49. Keller-Juslen C, Kuhn M, Von Wartburg A, Stähelin H (1971) Mitosisinhibiting natural products. 24. Synthesis and antimitotic activity of glycosidic lignan derivatives related to podophyllotoxin. J Med Chem 14(10):936-940

50. Ardalani H, Avan A, Ghayour-Mobarhan M (2017) Podophyllotoxin: a novel potential natural anticancer agent. Avicenna J Phytomed 7(4):285
51. Giri A, Narasu ML (2000) Production of podophyllotoxin from Podophyllum hexandrum: a potential natural product for clinically useful anticancer drugs. Cytotechnology 34(1-2):17-26

52. Wang Z, Olumi AF (2011) Diabetes, growth hormone-insulin-like growth factor pathways and association to benign prostatic hyperplasia. Differentiation 82(4-5):261-271

\section{Publisher's note}

Springer Nature remains neutral with regard to jurisdictional claims in published maps and institutional affiliations.

\section{Submit your manuscript to a SpringerOpen ${ }^{\circ}$ journal and benefit from:}

- Convenient online submission

- Rigorous peer review

- Open access: articles freely available online

- High visibility within the field

- Retaining the copyright to your article

Submit your next manuscript at $\gg$ springeropen.com 